\title{
Incidence of acute radiodermatitis in women with breast cancer undergoing hypofractionated radiotherapy
}

\author{
Incidência de radiodermatite aguda em mulheres com câncer de mama submetidas à radioterapia hipofracionada \\ Incidencia de radiodermatitis aguda en mujeres con cáncer de mama sometidas a la radioterapia hipofraccionada
}

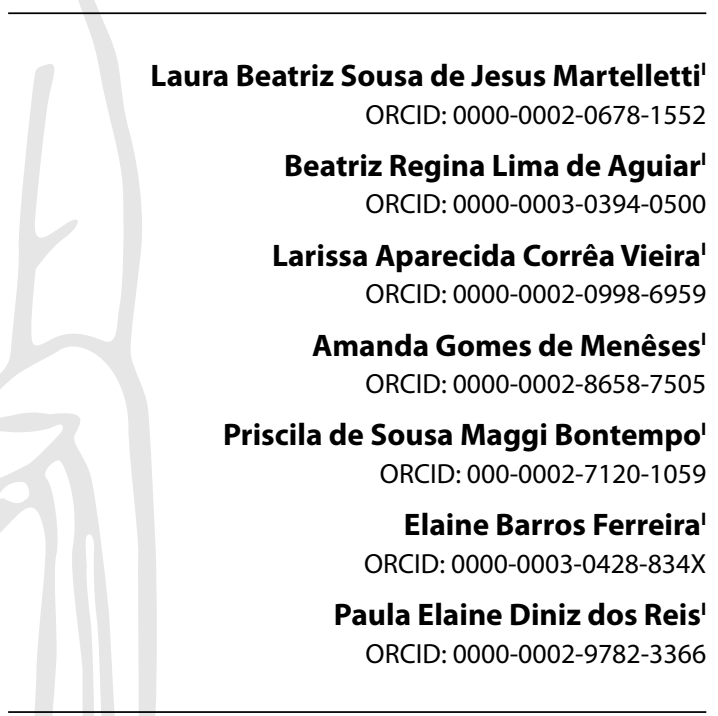

'Universidade de Brasília. Brasília, Distrito Federal, Brazil.

How to cite this article: Martelletti LBSJ, Aguiar BRL, Vieira LAC, Menêses AG, Bontempo PSM, Ferreira EB, et al. Incidence of acute radiodermatitis in women with breast cancer undergoing hypofractionated radiotherapy.

Rev Bras Enferm. 2022;75(1):e20210118. http://doi.org/10.1590/0034-7167-2021-0118

Corresponding author:

Laura Beatriz Sousa de Jesus Martelletti E-mail: laurabeatriz.unb@gmail.com

EDITOR IN CHIEF: Antonio José de Almeida Filho ASSOCIATE EDITOR: Ana Fátima Fernandes

Submission: 03-17-2021

Approval: 04-22-2021

\section{ABSTRACT}

Objective: To estimate the incidence and degree of acute radiodermatitis at the end and after the end of treatment in women with breast cancer undergoing hypofractionated radiotherapy. Methods: Observational, prospective, and longitudinal study, conducted between March 2019 and January 2020, in a radiotherapy outpatient clinic. Results: Thirtytwo women participated in the study, among whom, in the last session of hypofractionated radiotherapy, $15(46.9 \%)$ had radiodermatitis, erythema in $13(40.6 \%)$, and wet peeling in 2 (6.3\%). In the post-treatment evaluation, 27 (84.4\%) had radiodermatitis, erythema in 17 $(53.1 \%)$, dry peeling in $8(25 \%)$, and wet peeling in $2(6.3 \%)$. Conclusion: The general incidence of radiodermatitis after hypofractionated radiotherapy in women with breast cancer was $37.5 \%$, erythema, $12.5 \%$, and dry peeling, $25 \%$. The development of care protocols for the management of radiodermatitis after treatment is of paramount importance.

Descriptors: Radiodermatitis; Radiotherapy; Radiation dose Hypofractionation; Breast Neoplasms; Oncology Nursing.

\section{RESUMO}

Objetivo: Estimar a incidência e o grau de radiodermatite aguda ao final e após o término do tratamento em mulheres com câncer de mama submetidas à radioterapia hipofracionada. Métodos: Estudo observacional, prospectivo e longitudinal, realizado entre março de 2019 e janeiro de 2020, em um ambulatório de radioterapia. Resultados: Participaram do estudo 32 mulheres, dentre as quais, na última sessão de radioterapia hipofracionada, 15 $(46,9 \%)$ apresentavam radiodermatite, sendo eritema em $13(40,6 \%)$ e descamação úmida em $2(6,3 \%)$. Na avaliação após o tratamento, $27(84,4 \%)$ apresentavam radiodermatite, sendo eritema em 17 (53,1\%), descamação seca em 8 (25\%) e descamação úmida em 2 (6,3\%). Conclusão: A incidência geral de radiodermatite após radioterapia hipofracionada em mulheres com câncer de mama foi 37,5\%: eritema, 12,5\%; e descamação seca, $25 \%$. É de suma importância o desenvolvimento de protocolos assistenciais para o manejo de radiodermatite após o tratamento.

Descritores: Radiodermatite; Radioterapia; Hipofracionamento da Dose de Radiação; Neoplasias da Mama; Enfermagem Oncológica.

\section{RESUMEN}

Objetivo: Estimar la incidencia y el grado de radiodermatitis aguda al final y después el término del tratamiento en mujeres con cáncer de mama sometidas a la radioterapia hipofraccionada. Métodos: Estudio observacional, prospectivo y longitudinal, realizado entre marzo de 2019 y enero de 2020, en un ambulatorio de radioterapia. Resultados: Participaron del estudio 32 mujeres, de entre las cuales, en la última sesión de radioterapia hipofraccionada, $15(46,9 \%)$ presentaban radiodermatitis, siendo eritema en $13(40,6 \%)$ y descamación húmeda en 2 (6,3\%). En la evaluación después del tratamiento, 27 (84,4\%) presentaban radiodermatitis, siendo eritema en $17(53,1 \%)$, descamación seca en $8(25 \%)$ y descamación húmeda en $2(6,3 \%)$. Conclusión: La incidencia general de radiodermatitis después radioterapia hipofraccionada en mujeres con cáncer de mama fue 37,5\%: eritema, $12,5 \%$; y descamación seca, $25 \%$. Es de suma importancia el desarrollo de protocolos asistenciales para el manejo de radiodermatitis después del tratamiento.

Descriptores: Radiodermatitis; Radioterapia; Hipofraccionamiento de la Dosis de Radiación; Neoplasias de la Mama; Enfermería Oncológica. 


\section{INTRODUCTION}

Breast cancer is the most incident in women in Brazil and the second most prevalent in the world ${ }^{(1-2)}$. Radiotherapy is a therapeutic modality widely used as neoadjuvant or adjuvant therapy ${ }^{(2-3)}$. Conventional radiotherapy protocols for breast cancer often use a total dose of ionizing radiation between 45.0 to 50.4 Gray (Gy), fractional in daily applications of 1.8 to $2.0 \mathrm{~Gy}$, five days a week, lasting five to six weeks ${ }^{(4-5)}$.

With the advancement of therapeutic techniques, possibilities have emerged to reduce the time and cost of radiotherapy for breast cancer. In this context, we highlight hypofractionated radiotherapy, which consists of a technique in which the patient receives a higher dose of ionizing radiation per fraction and has a shorter duration than the conventional Protocol ${ }^{(4)}$. According to the recommendations of the Brazilian Society of Radiotherapy, safe planning is based on a total dose of 40.0 to $42.5 \mathrm{~Gy}$, divided into $2.66 \mathrm{~Gy}$ per fraction, which corresponds to a protocol of 15 to 16 fractions, lasting three weeks ${ }^{(4)}$.

Although the ionizing radiation beam is directed to the tumor, the cutaneous tissue receives high doses of this radiation and, due to its characteristic of high proliferative capacity, has greater sensitivity to radiotoxicity ${ }^{(6)}$, known as radiodermatitis (RD). Acute $\mathrm{RD}$ is a skin reaction that can appear from the beginning of treatment up to three months after the end of radiotherapy and affects about $80 \%$ to $98 \%$ of patients with breast cancer submitted to this technique ${ }^{(2,7)}$, which can compromise the continuity of treatment and the quality of life of patients $\mathrm{s}^{(8-9)}$.

The severity of RD is related to intrinsic factors, that is, related to the patient (smoking, alcoholism, breast size, and body mass index - BMI); and extrinsic, related to treatment (concomitant hormonal treatment, planning techniques, and dose distribution) ${ }^{(10-11)}$. The dedependent character of RD is highlighted, i.e., its severity is directly related to the accumulated dose of ionizing radiation over time ${ }^{(2,7)}$.

A meta-analysis of 23 studies did not identify a significant difference in the occurrence of acute $\operatorname{RD}(p=0.72)$ in patients undergoing hypofractionated radiotherapy compared to conventional post-mastectomy radiotherapy ${ }^{(5)}$. However, the authors do not specify the period for the evaluation of acute RD and the followup of the patients of the studies included in the meta-analysis, which prevents an accurate evaluation of the incidence of acute $\mathrm{RD}$ after the end of radiotherapy, when the patients have already received the total dose of ionizing radiation.

There is a gap in the measurement of the occurrence of acute $\mathrm{RD}$ after hypofractionated radiotherapy. Ippolito et al. ${ }^{(12)}$, who deal with boost dose escalation in breast cancer patients undergoing hypofractionated radiotherapy, analyzed secondarily the data on the occurrence of acute RD during, in the end, and three months after treatment. All participants $(n=09)$ presented some degree of RD during and at the end of treatment, and, after three months, $44.4 \%$ ( $n=04$ ) showed grades 1 and 3 . However, the reduced sample size limits the reliability of the results.

\section{OBJECTIVE}

To estimate the incidence and degree of acute radiodermatitis in women with breast cancer undergoing hypofractionated radiotherapy, at the end and after the end of treatment.

\section{METHODS}

\section{Ethical aspects}

The study was approved by the Research Ethics Committee (REC) of the College of Health Sciences of the University of Brasilia (FS/UnB). Only the participants who consented to participate in the research expressing their acceptance by signing the free and informed consent form and authorized the use of the photographic documentation of the irradiated area (Authorization Term for Image Use) were included.

\section{Design, period and place of study}

An observational, prospective, longitudinal study based on the Strengthening the Reporting of Observational Studies in Epidemiology (STROBE) ${ }^{(13)}$. Data collection was performed between March 2019 and January 2020 at the radiotherapy outpatient clinic of the University Hospital of Brasilia, Federal District, Brazil.

\section{Population; criteria of inclusion and exclusion}

The target population was women aged 18 years or older, diagnosed with breast cancer, and who had completed hypofractionated radiotherapy.

The eligibility criteria for sample selection were: women aged 18 years or older, diagnosed with breast cancer, submitted to hypofractionated radiotherapy for the first time, with the skin of the irradiated area intact. The patients were recruited during the nursing consultation on the last day of hypofractionated radiotherapy.

\section{Study protocol}

For data collection, we used an instrument built by the authors for this purpose. The sociodemographic and clinical data collected were: age (in years, on the day of the first appointment), education, skin type (Fitzpatrick phototype classification) ${ }^{(14)}$, smoking, and alcohol status (never, interrupted for more than six months/ less than six months, currently), diabetes (yes/no), hypothyroidism (yes/no), skin disease (yes/no), statin use (yes/no), tumor staging, current treatment, amount of Sessions, dose fractional (in Gy), total accumulated radiation dose (in Gy).

The skin was evaluated according to the classification criteria of $\mathrm{RD}$, graduation of acute radiodermatitis, as the following: 0 (unchanged), $1 \mathrm{a}$ (hyperpigmentation or mild erythema), $1 \mathrm{~b}$ (intense erythema), $2 a$ (dryness of the skin), $2 b$ (dry desquamation located at one or more separate points), 2c (dry desquamation disseminated at one or more points in contiguity), 3a (moist desquamation in folds), $3 \mathrm{~b}$ (moist desquamation disseminated), 4 (bleeding and/or ulceration) and 5 (necrosis) ${ }^{(15)}$. The symptoms presented were also graded, namely: 0 (unchanged), 1 (local Heat), 2 (burning), 3 (itching), 4 (report of rough, dry, and/or jerking skin), and 5 (pain), knowing that the symptoms may or may not be associated with the signs and vary in each patient ${ }^{(15)}$.

Photographic records were made of the irradiated mammary region subject to evaluation. The photos were made in a standardized way, respecting conditions such as patient distance and 
lighting and using the same camera for each patient (Smartphone Asus Zenfone Max Shot 64GB, screen 6,2" Full HD Plus, Octa-Core, triple camera $12 \mathrm{MP}+5 \mathrm{MP}+8 \mathrm{MP})$. The identity of the participants involved in the research was preserved.

The patients were evaluated in two different moments: in the nursing appointment of the last session of hypofractionated radiotherapy, and the return appointment that the patient is discharged from treatment.

\section{Analysis of results and statistics}

For the analysis of the data, we used descriptive and inferential statistics through the Statistical Package for the Social Sciences (SPSS) software, version 22.0.

The incidence of RD was measured based on the cutaneous evaluation at the last session of hypofractionated radiotherapy compared to the cutaneous evaluation at the return visit, with a mean difference of 11 days between the evaluations. Confidence intervals were adopted for the occurrence of each degree of RD, considering a significance index of $5 \%$. We presented the sociodemographic and clinical characteristics in a descriptive manner.

\section{RESULTS}

We evaluated 32 women diagnosed with breast cancer submitted to hypofractionated radiotherapy. The participants were between 37 and 86 years old on the day of the first appointment. The predominant level of education among them was incomplete elementary education (34.4\%). Skin type: $56.3 \%$ were phototype III (light brown, standard sensitivity, and moderately burning) according to the Fitzpatrick scale ${ }^{(14)}$.

Regarding the histopathological type of the tumor, $84.4 \%$ of the patients were diagnosed with infiltrative ductal carcinoma. Staging: stage IIB (tumor between $20 \mathrm{~mm}$ and $50 \mathrm{~mm}$ with metastasis in ipsilateral mobile axillary lymph nodes) ${ }^{(16)}$ was the most prevalent in the sample, present in $28.1 \%$ of the participants, followed by IIIA (tumor bigger than $50 \mathrm{~mm}$ with metastasis in clinically fixed level I or II ipsilateral lymph nodes; or isolated metastasis in ipsilateral internal breast chain lymph nodes) ${ }^{(16)}$, present in $18.8 \%$ of the samples.

Other data of sociodemographic and clinical characterization of the participants are presented in Table 1.

The patients were treated in radiotherapy devices, of linear accelerators type, manufacturer Varian ', CLINAC CX model, or SIEMENS ${ }^{\circ}$, PRIMUS model, using three-dimensional conformational planning (3D-CRT) with hypofractionation protocol (2.65 to $2.90 \mathrm{~Gy}$ per fraction). On average, patients underwent 16 (SD 1.3) sessions of hypofractionated radiotherapy. The majority $(68.8 \%, \mathrm{n}=22)$ had four irradiated breast regions, namely: supra-clavicular, frontal, axillary, and infra-mammary sulcus. In the others, three regions were irradiated with the exception of the supraclavicular region.
Regarding the general estimate of the occurrence of RD, on the last day of hypofractionated radiotherapy, 15 (46.9\%) participants presented some degree of RD; and upon returning to the service, on average 11 days after the end of treatment, 27 (84.4\%) had some degree of RD, so the general incidence of RD after hypofractionated radiotherapy was $37.5 \%$.

Table 1 - Characterization of the sample $(\mathrm{N}=32)$ regarding sociodemographic and clinical aspects, Brazil, 2020

\begin{tabular}{lc}
\hline Characteristics & $\begin{array}{c}\mathbf{N}=\mathbf{3 2} \\
\text { average (DP*) }\end{array}$ \\
\hline Age (in years) & $53(12.81)$ \\
BMI* $^{*}$ & $27.52(5.2)$ \\
Chest circumference (in cm*) & $96.13(11)$ \\
Smoking Status & $\mathrm{n}(\%)$ \\
Never & $21(65.6)$ \\
Interrupted for more than six months & $10(31.3)$ \\
Current usage & $1(31.1)$ \\
Alcohol Status & $\mathrm{n}(\%)$ \\
Never & $17(53.1)$ \\
Interrupted for more than six months & $8(25.0)$ \\
Discontinued in the last six months & $1(3.1)$ \\
Current usage & $6(18.8)$ \\
Comorbidities (yes) & $\mathrm{n}(\%)$ \\
Diabetes & $6(18.8)$ \\
Hypothyroidism & $1(3.1)$ \\
Use of statins & $5(15.6)$ \\
Skin disease & $1(3.1)$ \\
Current treatment type & $\mathrm{n}(\%)$ \\
Exclusive RTHF* & $14(43.8)$ \\
Concomitant hormone therapy & $18(56.3)$ \\
RTHF (in Gy*) & $a v e r a g e(D P)$ \\
Dose per fraction & $2.67(0.04)$ \\
Total cumulative dose & $42.40(3.39)$ \\
\hline
\end{tabular}

* Note: SD: standard deviation; BMI: Body Mass Index; cm: centimeters; RTHF: hypofractionated radiotherapy; Gy: Gray.

Table 2 - Occurrence and incidence by the degree of radiodermatitis after hypofractionated radiotherapy $(\mathrm{N}=32)$, Brazil, 2020

\begin{tabular}{lccccc}
\hline Outcome & \multicolumn{2}{c}{$\begin{array}{c}\text { Occurrence of } \\
\text { radiodermatitis on } \\
\text { the last day of RTHF* }\end{array}$} & \multicolumn{2}{c}{$\begin{array}{c}\text { Occurrence of } \\
\text { radiodermatitis } \\
\text { after RTHF* }\end{array}$} & $\begin{array}{c}\text { Incidence of } \\
\text { radiodermatitis } \\
\text { after RTHF* }\end{array}$ \\
& $\mathbf{n}(\%)$ & IC* $\mathbf{9 5 \%}$ & $\mathbf{n}(\%)$ & IC* 95\% & (\%) \\
\hline Erythema & $13(40.6)$ & $25.0-56.3$ & $17(53.1)$ & $37.5-71.9$ & 12.5 \\
$\begin{array}{l}\text { Dry desquamation } \\
\text { Moist desquamation }\end{array}$ & - & - & $8(25.0)$ & $12.5-40.6$ & 25.0 \\
\hline
\end{tabular}

${ }^{*}$ Note: $\mathrm{Cl}$ - confidence interval; RTHF-hypofractionated radiotherapy.

As for the symptoms in the treatment region on the last day of hypofractionated radiotherapy, 10 (31.3\%) women presented itching, 7 (21.9\%) reported feeling dry, rough, dry, and/or jerking skin, 5 (15.6\%) reported pain, 4 (12.5\%) reported local heat, and 3 $(9.4 \%)$, reported burning. Symptoms were not measured after treatment due to the dynamics of the return-to-discharge appointment. Table 2 shows the results for occurrence and graduation of RD. 


\section{DISCUSSION}

This is the first Brazilian study to estimate the incidence and degree of acute RD after hypofractionated radiotherapy in patients with breast cancer. The general occurrence of RD in the first evaluation was $46.9 \%$, and in the second, $84.4 \%$. Regarding the overall incidence of RD, 37.5\% new cases were estimated after hypofractionated radiotherapy, with the incidence of erythema $12.5 \%$; dry desquamation, $25 \%$; and there were no new cases of moist desquamation.

Hypofractionated radiotherapy for breast cancer has been used in the world, being a strategy that treats more patients in less time, safely and effectively, as much as conventional fractionation radiotherapy. A German study identified that university hospitals are the institutions that most use this therapeutic protocol ${ }^{(17)}$, a scenario similar to that of the present study, although it also found that the implementation of hypofractionated radiotherapy has been slow, even after guidelines recommend the use of this type of fractionation. The caveats found were increased side effects, impaired toxicity profile, and insufficient data, which contrasts strongly with the literature ${ }^{(17-18)}$.

In Systematic Reviews ${ }^{(19-21)}$ comparing conventional radiotherapy with hypofractionated radiotherapy, we have not found any statistically significant differences regarding local tumor recurrence, distant metastasis, overall survival, and disease-free survival. On the other hand, regarding the occurrence of acute $\mathrm{RD}$ during the respective treatments, there was statistically significant favor in the use of hypofractionation ( $p$ $\left.=0.0003^{(19)} ; \mathrm{p}<0.0001^{(20)} ; \mathrm{p}=0.02^{(21)}\right)$. However, we observed high heterogeneity between the studies.

Yamazaki et al. ${ }^{(22)}$ compared RD in therapies with hypofractionation and conventional radiotherapy in patients with breast cancer post-conservative surgery. The evaluations were made before starting treatment and every other day during radiotherapy, and the authors did not identify statistically significant difference between the two groups for the different degrees of RD.

Our clinical experience in the radiotherapy service pointed out different data from those presented in the literature. We observed that breast cancer patients submitted to hypofractionated radiotherapy were developing $\mathrm{RD}$ after the end of treatment. The overall estimate of the occurrence of RD after hypofractionated radiotherapy, identified in this study, reached $84.4 \%$, of which $6.3 \%$ presented moist desquamation, which may be associated with possible local infections hindering the management and recovery of the patient's skin ${ }^{(15)}$. It reinforces that the development or worsening of RD signs may be present in the post-treatment period.

The occurrence of erythema and dry desquamation is commonly related to symptoms such as itching, burning, and pain. In this study, the complaint most reported by the participants (31\%) on the last day of hypofractionated radiotherapy was pruritus. Fuzissaki et al. ${ }^{(9)}$ show that there is a deterioration in the quality of life concerning symptoms of RD, which impacts the functionality and daily life of patients, with worsening according to the presence of more severe degrees of RD.
In a systematic review of radiation-induced skin toxicity, Yee et al. ${ }^{(23)}$ consider that new radiotherapy methods are the most important strategies for reducing RD in the future. Ultrahypofractionation techniques are already being tested and show promise; they configure doses $5.2 \mathrm{~Gy}$ per fraction in just one week of treatment, totaling $26 \mathrm{~Gy}^{(24)}$. However, based on the results of this study, we warn of the need for follow-up after hypofractionated radiotherapy since radio induced effects take time to appear on the skin surface and may not be identified during treatments that have a shorter duration.

\section{Limitations of the study}

The small sample size is one of the limitations of this work. However, even so, it has already been possible to observe the high occurrence of RD and reiterate the need to draw strategies to minimize this problem.

Another limitation is related to the difficulty of follow-up of patients; thus, we evaluate them only at the discharge visit, which occurred, on average, 11 days after the end of hypofractionated radiotherapy. Therefore, it is possible that the manifestation of $\mathrm{RD}$ to more severe degrees, such as moist desquamation and ulceration, may have been underreported since it is natural that mild or moderate degrees of RD not adequately treated may evolve to more severe degrees.

There was no evaluation of symptoms during the discharge appointment. Considering that the development of radiodermatitis is late in patients undergoing hypofractionated radiotherapy, the evaluation of symptoms is a relevant parameter and should be considered and included in future studies with this population.

\section{Contributions to the field of Nursing, Health or Public Policy}

Since the high incidence and occurrence of RD in patients after the end of hypofractionated radiotherapy, we emphasize the importance of their follow-up as they are no longer being assisted by the service due to the end of treatment. RD and its associated symptoms can be frightening and complex for patients to manage on their own after the end of their bond with the radiotherapy service. Thus, it is necessary to develop follow-up strategies and protocols to assist them properly after the end of treatment, considering that more severe degrees of RD can be a gateway to infections, requiring specialized management, as well as negatively interfere in the self-image and quality of life of women ${ }^{(15-23)}$.

Educational manuals aimed at the self-care of patients are accessible and easy to share technologies and can transmit knowledge regarding the management of radiotoxicity for patients with breast cancer ${ }^{(25)}$. In addition, remote care should be considered since, in the Brazilian scenario, many patients do not reside in the city where it is offered, and also because radiotherapy is a highly complex service. Currently, call service has become a technology accessible to the population because there are public places that provide free access to the internet, and smartphones are already accessible resources in Brazilian families. 
However, if we consider that access may be difficult, another strategy is to establish contact with the counter reference service near the patient's place of residence. Thus, the nursing service of high complexity may be in contact with the primary care nurse to guide it regarding the evaluation of signs and symptoms and conduct in case of development of acute RD after the patient's discharge.

\section{CONCLUSION}

The overall incidence of $\mathrm{RD}$ after hypofractionated radiotherapy in women with breast cancer was 37.5\%: the incidence of erythema was $12.5 \%$, and dry desquamation was $25 \%$. No new cases of moist desquamation were identified.

Thus, it is of paramount importance to conduct studies with a more prolonged follow-up period in this population and the development of specialized care protocols for the management of this radiotoxicity after the end of hypofractionated radiotherapy.

\section{FUNDING}

The research was developed with the support of the social demand scholarship CAPES (Coordination for the Improvement of Higher Education Personnel Foundation).

\section{ACKNOWLEDGMENTS}

We thank the collaboration of CAPES, which made possible the arrival of the foreign visit of the professor Márcia Ciol (Public Notice CAPES Print, University of Brasilia), whose discipline taught enabled the improvement of this manuscript.

\section{REFERENCES}

1. Instituto Nacional de Câncer José Alencar Gomes da Silva. Coordenação de Prevenção e Vigilância. Estimativa 2020: incidência de câncer no Brasil [Internet]. Rio de Janeiro: INCA, 2019. Available from: https://www.inca.gov.br/publicacoes/livros/estimativa-2020-incidencia-de-cancer-no-brasil

2. Costa CC, Lyra JS, Nakamura RA, Sousa CM. Radiodermatitis: análise dos fatores preditivos em pacientes com câncer de mama. Rev Bras Cancerol. 2019;65(1):e-05275. https://doi.org/10.32635/2176-9745.RBC.2019v65n1.275

3. Hashemi FA, Barzegartahamtan M, Mohammadpour RA, Sebzari A, Kalaghchi B, Haddad P. Comparison of conventional and hypofractionated radiotherapy in breast cancer patients in terms of 5-year survival, locoregional recurrence, late skin complications and cosmetic results. Asian Pac J Cancer Prev. 2016;17(11):4819-23. https://doi.org/10.22034/APJCP.2016.17.11.4819

4. Freitas NMA, Rosa AA, Marta GN, Hanna SA, Hanriot RM, Borges ABB, et al. Recommendations for hypofractionated whole-breast irradiation. Rev Assoc Med Bras. 2018;64(9):770-7. https://doi.org/10.1590/1806-9282.64.09.770

5. Liu L, Yang Y, Guo Q, Ren B, Peng Q, Zou L, et al. Comparing hypofractionated to conventional fractionated radiotherapy in postmastectomy breast cancer: a metaanalysis and systematic review. Radiat Oncol. 2020;15(1):1-15. https://doi.org/10.1186/s13014-020-1463-1

6. Ruysscher D, Niedermann G, Burnet NG, Siva S, Lee AWM, Hegi-Johnson F. Radiotherapy toxicity. Nat Rev Dis Primers. 2019;5(1):13. https://doi. org/10.1038/s41572-019-0064-5

7. Cardozo AS, Simões FV, Santos VO, Portela LF, Silva RC. Severe radiodermatitis and risk factors associated in head and neck cancer patients. Texto Contexto Enferm. 2020;29:e20180343. https://doi.org/10.1590/1980-265x-tce-2018-0343

8. Beamer LC, Grant M. Longitudinal trends in skin-related and global quality of life among women with breast radiodermatitis: a pilot study. Eur J Oncol Nurs. 2018;33:22-7. https://doi.org/10.1016/j.ejon.2018.01.008

9. Fuzissaki MA, Paiva CE, Oliveira MA, Canto PPL, Maia YCP. The impact of radiodermatitis on breast cancer patients' quality of life during radiotherapy: a prospective cohort study. J Pain Symptom Manage. 2019;58(1):92-9. https://doi.org/10.1016/j.jpainsymman.2019.03.017

10. Kole AJ, Kole L, Moran MS. Acute radiation dermatitis in breast cancer patients: challenges and solutions. Breast Cancer (Dove Med Press). 2017;9:313-23. https://doi.org/10.2147/bctt.s109763

11. Langhe S, Mulliez T, Veldeman L, Remouchamps V, Van Greveling A, Gilsoul M, et al. Factor modifying the risk for developing acute skin toxicity after whole-breast intensity modulated radiotherapy. BMC Cancer. 2014;14: 711. https://doi.org/10.1186\%2F1471-2407-14-711

12. Ippolito E, Rinaldi CG, Silipigni S, Greco C, Fiore M, Sicilia A, et al. Hypofractionated radiotherapy with concomitant boost for breast cancer: a dose escalation study. Br J Radiol. 2019;92:20180169. https://doi.org/10.1259/bjr.20180169

13. Malta M, Cardoso LO, Bastos FI, Magnanini MMF, Silva CMFP. Iniciativa STROBE: subsídios para a comunicação de estudos observacionais. Rev Saúde Pública. 2010;44(3):559-65. https://doi.org/10.1590/S0034-89102010000300021

14. Fitzpatrick BT. The validity and practicality of sun reactive skin types I through VI. Arch Dermatol. 1988;124(6):869-71. https://doi.org/10.1001/ archderm.1988.01670060015008

15. Reis PED, Ferreira EB, Bontempo PMS. Radiodermatites: prevenção e tratamento. In: Diretrizes Oncológicas 2. p. 683-692. Doctor press: Ed. Científica. São Paulo, 2019.

16. Andrade AMGMC, Rocha CHL, Barbalho DM, Silva DFR, Siqueira GSM, Neto JNM. Câncer de mama. In: Diretrizes Oncológicas 2. p. 683-692. Doctor press: Ed. Científica. São Paulo, 2019.

17. Krug D, Vonthein R, Schreiber A, Boicev AD, Zimmer J, Laubach R, et al. Impact of guideline changes on adoption of hypofractionation and breast cancer patient characteristics in the randomized controlled HYPOSIB trial. Strahlenther Onkol. 2020;15:1-10. https://doi.org/10.1007/ s00066-020-01730-9 
18. Mayinger M, Straube C, HabermehI D, Duma MN, Combs SE. Hypo- vs. normofractionated radiation therapy in breast cancer: a patterns of care analysis in German speaking countries. Rep Pract Oncol Radiother. 2020;25:775-9. https://doi.org/10.1016/j.rpor.2020.07.003

19. Andrade TRM, Fonseca MCM, Segreto HRC, Segreto RA, Martella E, Nazário ACP. Meta-analysis of long-term efficacy and safety of hypofractionated radiotherapy in the treatment of early breast cancer. Breast. 2019;48:24-31. https://doi.org/10.1016/j.breast.2019.08.001

20. Hickey BE, James ML, Lehman M, Hider PN, Jeffery M, Francis DP, et al. Hypofractionated radiation therapy for early breast cancer. Cochrane Database System Rev. 2016;7:CD00386. https://doi.org/10.1002/14651858.CD003860.pub4

21. Zhou ZR, Mei X, Chen XX, Yang ZZ, Hou J, Zhang L, et al. Systematic review and meta-analysis comparing hypofractionated with conventional fraction radiotherapy in treatment of early breast cancer. Surg Oncol. 2015;24:200e11. https://doi.org/10.1016/j.suronc.2015.06.005

22. Yamazaki H, Takenaka T, Aibe N, Suzuki G, Yoshida K, Nakamura S, et al. Comparison of radiation dermatitis between hypofractionated and conventionally fractionated postoperative radiotherapy: objective, longitudinal assessment of skin color. Scienti Rep. 2018;8(12306):1-8. https:// doi.org/10.1038/s41598-018-30710-4

23. Yee C, Wang K, Asthana R, Drost L, Lam H, Lee J, et al. Radiation-induced skin toxicity in breast cancer patients: A systematic review of randomized trials. Clin Breast Cancer. 2018;18(5):E825-40. https://doi.org/10.1016/j.clbc.2018.06.015

24. Murray BA, Haviland JS, Wheatley DA, Sydenham MA, Alhasso A, Bloomfield DJ, et al. Hypofractionated breast radiotherapy for 1 week versus 3 weeks (FAST-Forward): 5-year efficacy and late normal tissue effects results from a multicentre, non-inferiority, randomised, phase 3 trial. Lancet. 2020;23;395(10237):1613-26. https://doi.org/10.1016/S0140-6736(20)30932-6

25. Cruz FOAMC, Faria ET, Reis PED. Validation of an education manual for breast cancer patients undergoing radiotherapy. Rev Latino-Am Enfermagem. 2020;(28):e3384. https://doi.org/10.1590/1518-8345.3197.3384 